\title{
Fads and Fancies: The Use of New Management Tools in UK Universities
}

\author{
John Taylor ${ }^{\mathrm{a}}$ \\ ${ }^{a}$ University of Liverpool, United Kingdom
}

\begin{abstract}
Over the last 20 years, British universities have often looked to business for ideas that might help them cope with growing financial and competitive pressures, increasing expectations of quality and new forms of accountability. The impact of this "new managerialism" has been researched in broad terms, especially looking at the inter-relationship between academic staff and university managers. By contrast, very little has been written about one, highly practical expression of the new managerialism, namely the use of new management tools. This paper brings together separate studies of three such tools: the balanced scorecard, knowledge management and lean thinking. In each case, issues of motivation, leadership and implementation are considered, leading to an overall set of factors that influence the use of such tools in higher education and a model for wider consideration.
\end{abstract}

\begin{abstract}
Abstrak
Selama dua puluh tahun terakhir, universitas-universitas di Inggris banyak menggali ide dari sektor bisnis untuk membantu mengatasi tekanan keuangan dan kompetisi yang makin meningkat, standar kualitas yang makin tinggi dan format akuntabilitas baru. Dampak dari manajerialisme baru ini telah diteliti secara luas, terutama hubungan antara staf akademis dan manajer universitas. Tapi, hanya sedikit yang menulis tentang manajerialisme baru yang sangat praktis ini, yaitu penggunaan instrumen manajemen baru. Makalah ini menggabungkan beberapa studi berbeda tentang tiga instrumen manajemen: balanced scorecard, knowledge management, dan lean thinking. Pada masing-masing studi, berbagai isu tentang motivasi, kepemimpinan dan implementasi juga dikaji, dengan mengarah pada faktor-faktor yang mempengaruhi penggunaan instrument tersebut di perguruan tinggi dan sebuah model untuk dikaji lebih jauh.
\end{abstract}

Key Words: Leadership, Management, Organization, Motivation, Quality

\section{Introduction}

Much has been written in recent years about the emergence of new managerialism in higher education institutions and, in particular, the application of ideas from business within publicly funded universities. Rosemary Deem (2001) sees the concept of new managerialism as referring both to "ideologies about the application of techniques, values and practices derived from the private sector to the management of organizations concerned with the provision of public services" and to "the actual use of those techniques and practices in publicly funded organizations” (10). Rosemary Deem and Kevin J. Brehony (2005) also distinguish

*Corresponding author. Address: University of Liverpool Management School, University of Liverpool, Chatham Street, Liverpool, L69 7ZH, United Kingdom. Email: john.taylor@liverpool.ac.uk. between "new managerialism," which they see primarily as an "ideological configuration of ideas and practices," and "new public management" which they see as, in essence, "the implementation of a particular form of regulatory governance of public services by state agencies” (219). In these debates, attention has centered upon the impact of such developments on governance, leadership, the reshaping of the academic profession and academic freedom, and much less on the techniques and practices themselves.

Closely related to the discussion of managerialism are issues of managing change in higher education. Given the massive pressures for change facing higher education, especially relating to increasing marketization and global competition, it is not surprising that universities may look to new management approaches as both a response to a changing environment and as a stimulus to further institutional change. In this process, the advocates of new

(c) BY-NC-ND This work is licensed under a Creative Commons Attribution-Noncommercial-No Derivative Works 3.0 United States License. ISSN 2153-9669 (print) 2153-9677 (online) | doi: 10.5195/ehe.2012.46 | http://ehe.pitt.edu 
managerialism may be found as much inside universities as outside. One area where such change is often most obvious within institutional management relates to the adoption of new management tools. Many new techniques have been imported from the business world for use in higher education in recent years, often greeted with suspicion and cynicism by academic staff. Commonly, these tools are dismissed as "fads and fancies," a phase that will pass; something that "if we ignore it, will go away." While important within university management, the process by which such methods are introduced and the practical issues arising have been little researched. Attention has focused more on the overall styles of leadership and management associated with new managerialism rather than its detailed practice. However, the application of these tools can help to shed further light on the practice of change management within higher education and can reveal lessons of wider relevance for institutional leadership. This article therefore considers the application of three particular new management techniques: the balanced scorecard, "lean” management and knowledge management. It aims to identify common factors that contribute to the successful or unsuccessful implementation of these tools within the wider context of change management in higher education.

\section{Management Tools}

In 1993, management consultants Bain \& Company began to track the use of management tools in business. Their latest report, published in 2011, listed 25 tools in terms of their popularity based on survey results from 1,230 international executives (Rigby and Bilodeau 2011). Such tools may be used to increase income, to reduce costs, to improve efficiency, to enhance strategy, to manage change and to improve quality. These are all pressures highly relevant for higher education today. The "top three" tools are all familiar within higher education-benchmarking, strategic planning, mission and vision statements - and most, if not all, the remaining tools would also be widely recognized within universities. Higher education is, therefore, already using these business tools. However, experience from the business world also shows that such tools should be seen to assist and support management; they are not in themselves a solution to any particular problem. They may also be expensive to implement and maintain, with potential risks of increasing cost and inefficiency as well as the prospect of operational improvement. It is important that these management tools are implemented as part of an integrated institutional strategy with clear objectives and means of delivery. In short, the use of new management tools may bring benefits, but it may also carry risks. The application of these tools within higher education, and especially within the publicly funded sector, therefore requires further research and consideration; good practice needs to be more clearly understood in order to minimize possible problems. Most important, perhaps, is the danger that the use of new management tools become a "fad" or a fashion, adopted without a local rationale because other institutions have moved in the same direction.

\section{Methodology}

This article is based on three separate studies of the use of three particular management tools. In each case, a qualitative approach was used, based upon semi-structured interviews with university leaders and managers and other university staff. Purposive sampling was used to select institutions with experience of the techniques in question and to identify staff with the relevant expertise and experience to enable useful comments and observations. The three sub-projects-identified as Case Study I, II, and III-are described separately, each with their own conclusions, before an overview is presented with some common outcomes.

\section{Case Study I: The Balanced Scorecard}

\section{Background}

Faced with growing pressures of competition and increasing requirements for accountability to both internal and external stakeholders, universities have become increasingly concerned with issues of performance at all levels within the organization. One response adopted by some universities has been the Balanced Scorecard.

The private sector has been concerned with the use of performance measurement models for many years. However, early approaches often lacked strategic focus (Skinner 1974), provided misleading signals for improvement and innovation (Kaplan and Norton 1992), encouraged short-term assessment (Hayes and Garvin 1982; McAdam and Bailie 2002), encouraged local optimism (Hall 1983) and failed to provide a focus on stakeholders and competition (Kaplan and Norton 1992). In response, in a series of iterative steps, Robert S. Kaplan and David P. Norton (1992, 1996, 2001) developed the Balanced Scorecard (BSC). The BSC aims to measure performance in four key areas:

- financial (i.e., how an organization views its stakeholders),

- customer (i.e., how customers view an organization),

- internal business environment (i.e., what an organization must excel at), and

- learning or organizational development (i.e., how an organization continues to improve and create value). 
In this way, the BSC is intended to provide a holistic, integrated view of business.

According to Karen Anderson and Rodney McAdam (2004), the BSC provides senior management with a clear organizational overview, but also has the problem of lacking key external and environmental measures. Internally, the BSC is commonly associated with enhanced communications, the development of common organizational objectives, the provision of effective feedback on new initiatives and the establishment of links between employee performance and corporate strategy. On the other hand, the BSC may be criticized for its strong internal focus, for creating a targetbased culture and for encouraging an over-emphasis on quantitative data without providing full analysis and understanding.

The BSC has been applied within higher education by many universities, initially in the US and more recently elsewhere in the world, notably in the UK and Australia. Given that higher education institutions are complex organizations with multiple and sometimes conflicting objectives, the development of tools that seek to provide an overview and to reconcile different priorities is highly attractive to many universities. In practice, the technique has been used both as a tool to support strategy development and as an approach to ensure accountability to senior management and to the institution as a whole. A clear strength of the BSC has been its adaptability to meet the specific needs of the institution.

\section{Research Findings}

In order to examine the application of the BSC in UK universities, a qualitative approach was used, based upon detailed case studies of four universities known to have adopted this technique. Fourteen interviews were undertaken with senior leaders and managers. The findings may be summarized as follows:

Motivation. Motivation for adopting the BSC varied between the institutions. Universities $\mathrm{X}$ and $\mathrm{Y}$, two of the earliest universities to use the technique in the UK (in 1998 and 2001 respectively), were motivated initially by the need to satisfy the requirements of corporate governance and compliance. In these cases, the BSC was used by the governing bodies to ensure that progress was maintained in implementing overall strategy. It was only more recently that both universities had looked to develop wider use and ownership of the BSC across other, more operational levels within the organization. Universities W and Z adopted the BSC in 2004 and 2007 respectively and were motivated much more by use of the BSC as a tool to help in implementing major corporate change.

In all four case studies, the arrival of a champion in the form of a newly appointed vice chancellor or principal or vice principal was significant in either the $a b$ initio adoption of measurement methodologies (Universities $\mathrm{W}$ and $\mathrm{Z}$ ) or the advancement of scorecards already in place (Universities $\mathrm{X}$ and $\mathrm{Y}$ ). The newly appointed vice chancellor of University $\mathrm{W}$ believed that his institution was not performing at a level appropriate to its size and status and saw the BSC as a means to help achieve the transformation he sought. It is striking that leadership and interest in performance management at the highest level were fundamental in the adoption of new forms of measurement. Referring to another new vice chancellor, a senior manager at University $\mathrm{Z}$ was clear that "it would not have happened without him; his personal commitment and views drove the whole process.” This vice chancellor wished to elevate the university to a significantly higher position within its peer group of institutions; a major concern, shared with University W, was getting "buy-in" across the institution and the BSC was seen to be a helpful tool towards this end. It was equally clear from all four cases that the motivation behind the use of the BSC was internal and driven from within the academic community; in none of the cases considered did the initiative to establish a BSC come either explicitly or implicitly from external stakeholders or from lay members of the governing body.

Implementation. All four universities gave very careful consideration to issues of implementation. Appropriate expertise was seen as vital. University $\mathrm{W}$ used external consultants, including specialist software. Other universities were less willing to commit resources at this level and preferred to use internal expertise.

In Universities $\mathrm{X}$ and $\mathrm{Z}$, the process of implementation, including discussions on the Key Performance Indicators (KPIs) to be included, was strongly centrally driven. By contrast, Universities $\mathrm{A}$ and $\mathrm{C}$ made significant efforts to engage widely in the development of targets within the BSC. University W established a project management infrastructure with formal groups, key events and targets, and a communications strategy to engage staff throughout the University. This approach provoked both positive and negative views. On the one hand, the methodology was established rapidly, effectively and consistently; on the other hand, one interviewee complained of an "unhelpful, military-style approach." Issues of centralization emerged in three of the case studies. A strength of the BSC is the development of a unitary approach across the institution, but the case studies showed that implementation required sensitivity and political awareness as well as central co-ordination and direction. Tensions could emerge where new techniques were applied across the whole institution and led from "the center," especially in universities that, for other reasons, had moved to more devolved structures (another management fad!); tensions with deeply rooted traditions of academic freedom were also apparent. 
Flexibility and Modifications. All four universities studied maintained the principle of balance across the selected perspectives, but also adapted the basic four-perspective scorecard of Kaplan and Norton to satisfy their specific institutional missions and circumstances. University W pursued an iterative approach leading to the selection of nine critical or "golden measures" out of 61 different metrics. By contrast, Universities B and C, probably by virtue of the relative maturity of their scorecards, used fewer measures (34 and 32 respectively); University D had 40 measures, spread equally across the four perspectives. This was a deliberate attempt to achieve "balance" in the approach. While balance is a key aspect of the Kaplan and Norton approach, evidence from the case studies suggests that other end-user values, such as focus and alignment with institutional mission, have to be taken into account in order to establish an effective tool.

The four universities recognized the need to adapt the language of the BSC in order to "fit" the needs of higher education. Academic leaders in all four universities were also wary of using "business language" within the university environment. University $\mathrm{X}$ used four labels as follows: Organizational Development, Financial Perspective, Stakeholder Perspective, and Internal Business Perspective. University Y referred even more simply to Finance, Students, Staff, and Other Perspectives.

The interviews show the perceived importance of terminology. For example, in University $\mathrm{X}$ a decision was reached to refer to students as "partners" rather than as "stakeholders." The use of acceptable language was crucial to the acceptance of the BSC methodology.

While Kaplan and Norton recognize that the BSC is intended as a template for local adaptation, they also emphasize that the BSC is a tool to support the measurement and implementation of strategy. Thus, the BSC needs to be linked with overall strategic objectives of the institution. In this context, the BSC used by University $\mathrm{X}$ did not conform in that it included measures that were not mission-critical such as reducing the number of university committees. This may be seen as a dilution of the true purpose of the BSC or, alternatively, it may simply be seen as an example of flexibility within the tool.

Direction of Travel. All the scorecards studied in this sub-project attempted to report on the direction of travel for each of the KPIs used. In initiating the scorecard, University $\mathrm{X}$ aimed to provide previous years' data on key metrics so that, even from the earliest phase of development, it was possible to identify trends. The webbased scorecard was also accompanied by graphical summaries of progress and change. University W was able to report on the direction of travel and on the velocity of change, using specialist BSC software that created a dashboard of the metrics. Within Universi- ty $\mathrm{W}$, this dashboard became a key tool for senior managers and leaders. Universities $\mathrm{Y}$ and $\mathrm{Z}$ both provided simple and clear statements of the level of achievement on a year-to-year basis.

Choice of KPIs was also crucial. University X indicated that it had actively sought to balance "lead" and "lag” measures. University Z indicated that their intention was to balance "pluses" and "minuses." Managers stressed the psychological importance of choosing some measures where the institution could be seen to be meeting its targets; in this way, staff would be more likely to take other, "less pleasing" targets more seriously.

A potential risk in the BSC approach identified in all four universities was the potential development of "a measurement industry." University X reviewed the KPIs in use to ensure that they reflected "need to know," not "nice to know." Each university took significant steps to define and document the data sources and to present appropriate assumptions and caveats about the use or interpretation of data. University W established a central administrative team with the specific remit of ensuring the clarity of the BSC and achieving a high degree of consensus on the fitness of purpose of all KPIs.

The case studies covered institutions that had adopted the BSC. A strong consensus emerged among those interviewed that the BSC offered a valuable tool for performance management, both as a tool to assist strategy formation and for subsequent reporting. In particular, the ease of understanding and ready access for all staff were stressed. The level of support is not surprising, but several interviewees indicated that initial doubts and skepticism had been won over. The case studies showed no evidence of the excessive bureaucracy that is sometimes associated with some methodologies; also, unlike dashboards and some other methodologies, the BSC could be implemented with major or minimal software investment depending on local priorities.

From the study, a checklist of key issues emerged:

- Universities need to clarify the users and audience for the BSC as this will shape the selection of KPIs.

- Strong, consistent leadership from the highest levels of the institution is crucial.

- A champion is needed to oversee implementation of the BSC.

- The scorecard must be linked directly with overall institutional strategy.

- A good spread of KPIs is needed, reflecting core objectives, mixing "lead" and "lag” measures and underpinned by real need; the BSC must not become a "compendium of management information.”

- Appropriate language and terminology must be used. 
- Visual presentation of the BSC is important for widespread use.

- Consideration needs to be given to possible relationships between the BSC and other university procedures, especially staff review and rewards.

For further detail on this project, see John Taylor and Claire Baines (2012).

\section{Case Study II: Lean Thinking}

\section{Background}

Lean thinking has its origins in the production system developed by the Toyota Motor Corporation in Japan in the 1950s. However, the idea of lean principles became familiar following the work undertaken within the International Motor Vehicle Program based at the Massachusetts Institute of Technology. In their seminal work, "The Machine That Changed the World" James P. Womack, Daniel T. Jones, and Daniel Roos (1990) described the transformation of the automobile industry into an era of mass production, offering the maximum value to the customer at minimum cost, thereby maximizing customer benefits. With the application of lean thinking, an organization creates a niche for itself by offering only those products and services that a customer needs, thereby achieving cost advantages by reducing all forms of muda (the Japanese term for "waste"). A further variation of the lean approach is a focus on the "flow" or smoothness of work, minimizing or eliminating unevenness and thereby reducing wasted resources.

A good idea of what is meant by lean thinking is offered by Mary Popendieck (2002, 1):

Lean thinking looks at the value chain and asks: How can things be structured so that the enterprise does nothing but add value, and does that as rapidly as possible? All the intermediate steps, all the intermediate time and all the intermediate people are eliminated. All that's left are the time, the people and the activities that add value for the consumer.

Building on this work, other scholars have sought to identify waste more closely. In particular, and relevant for service activities such as higher education, John Bicheno (2004) distinguished between seven forms of waste as viewed from a customer perspective: delay, duplication, unnecessary movement, unclear communication, incorrect inventory, opportunity lost, and errors in service provision.
Womack and Jones (2003) have also established five key principles for lean thinking as a guide for organizations seeking to move in this direction:

1. Specify value. Significantly, value can only be defined by the end consumer, not by the supplier.

2. Identify the value stream. Specifying the actions necessary to deliver a service or product, based on problem solving, information management and physical transformation.

3. Flow. Ensuring continuous flow from start to finish.

4. Pull. Designing and providing only what the customer wants, thereby reducing the inventory of products and reducing the time taken from design to production.

5. Perfection. The process of reducing effort, time, cost and resources, and of enhancing value to the consumer is neverending.

The potential applications of lean thinking to higher education have been recognized for many years. For example, Bob Emiliani (2004) and Clare L. Comm and Dennis F. X. Mathaisel (2003, 2005a, 2005b) argued that lean principles could be used to reduce waste and enhance customer value. Comm and Mathaisel (2003, 32) proposed a framework for the sustainable university using lean principles. They argued that, by the use of value stream mapping tools, universities could reduce cost, improve quality and increase student satisfaction:

Does the university optimize the scheduling and assignment of its resources (rooms and people)? Are professors and part-time instructors being adequately compensated for their productivity? Is the university over-promising what it can deliver to its customers? Are students experiencing very long wait times for services like registering for courses, eating in the cafeteria, obtaining grades?

Womack (2006) viewed higher education simply as another process or rather as three processes: design (knowledge creation and design of delivery); making and providing (knowledge transfer to undergraduates and postgraduates); and use (learning and knowledge transfer continuing through the life cycle). However, Peter Hines, Sarah Lethbridge, and Lucy O’Grady (2007) also showed that, while universities commonly attempted to improve their procedures, the use of holistic methodologies based around lean principles and organizational change was relatively unusual. 


\section{Research Findings}

Prima Facie, lean thinking is highly relevant to the higher education sector. Within an increasingly competitive national and international environment, the emphasis on meeting the needs of “customers" and stakeholders is extremely pertinent. Similarly, faced by financial pressures, the desirability of minimizing the wastage of resources (defined very broadly) is critical. It should also be emphasized that lean principles should not be seen purely as a means to save money, but also to enhance quality of provision, especially in service activities.

In order to explore the application of lean thinking in more detail, two case study institutions (A and B) were considered, both of which openly asserted their adoption of lean principles. A total of 15 interviews were undertaken, spanning senior leaders and managers and academic staff in both universities. The findings can be organized into ten categories and are summarized below.

Drivers of Change. In both universities, the main drivers for change were internal. While external pressures for change provided an important context, in each case the impetus to adopt lean principles came from senior management. In both universities, the vice chancellor and the senior executive group were highly proactive in promoting lean thinking as crucial in ensuring the longterm success of the institution. In some cases, particular local circumstances were also important. Thus, for University A, merger with another institution revealed internal inefficiencies and duplication in the delivery of services. In both universities, the drive for change was shaped by an overall vision and clear strategic objectives. A pro-vice-chancellor in University A stressed that "lean is only a tool, not an end in itself.”

Why Lean Thinking? In University A, the decision to adopt lean thinking was strongly motivated by the existence of substantial expertise in the field within the institution. At University B, lean principles were considered because of the perceived success of lean projects in other service organizations. A senior manager from University B explained that the University had experimented with other business practices and tools, such as benchmarking, and had internal expertise in tools such as Six Sigma and Total Quality Management. However, in his opinion, lean thinking was "simple, jargon-free and non-statistical” in its approach; the philosophy behind lean thinking was "easy to understand and easy to suit the University's requirements.” Leaders at University A believed that a key strength of lean principles was that they could be applied at any level in the organization and could be scaled to meet user requirements. Overall, lean ideas were seen as a customer-focused, value-driven approach that would achieve long-term, sustainable change.

Applying Lean Principles to Academic and Administrative Processes. Leaders and managers in both universities argued that, while objectives and the specific mode of operation might be different, a university was similar to many other service organizations in terms of the processes involved. Further, staff in both universities stressed that lean principles could be applied to both administrative and academic processes, including the pursuit of teaching and research. However, University B had chosen to apply lean principles, at least initially, only to administrative processes. This reflected both estimation that the benefits would be greater within administrative processes and an assessment of the relative ease of application.

Customers of the University. In both universities, all staff interviewed were clear that students should be viewed as end customers and emphasized the importance of improving customer focus and providing enhanced services. Other customers included parents, employers, government, business and research funding bodies. However, the universities acknowledged that the extent to which such ideas were shared within the institution could vary. In University A, it was recognized that "the notion of students as customers has not been widely accepted among the academic members of the University.” In University B, the use of business language such as customer service, corporate strategy, business improvement and efficiency gains had been widely encouraged and was now familiar throughout the organization. Nevertheless, it was also believed that some processes "could not be touched because they had always been done that way.”

Strategic Alignment and Structural Fit. The idea of the lean university was closely linked in both universities to the development and implementation of institutional strategic plans. An interviewee from University A argued that customers judge a university by its processes and by the technology, tools and techniques that deliver these processes. By contrast, the strategy, leadership and behavior underpinning such processes are much less visible to customers. Another leader referred to the difficulties in implementing lean principles given the changes in mind-set and culture that were needed, and emphasized that change was needed at the top of the organization and in decision-making procedures. He summed up the situation: "We are trying to apply lean through unlean university formal decision making structures.” Further, both universities were also seeking to pursue many other change programs. The challenge in implementing lean principles was to achieve "struc- 
tural fit and alignment of objectives” within the overall institutional strategy and alongside other competing priorities.

Leadership. The respondents from both universities believed that strong, transformational leadership was key to the success of a lean project. At University A, the vice chancellor had a strong business background that underpinned his commitment to the project. At University $B$, the head of the administration had championed the project with strong support from the vice chancellor. In both universities, it was also argued that the presence of small, highly committed teams operating across the whole institution had been crucial in supporting departments and front-line managers in implementing lean thinking. Such teams included both academic and administrative staff, which helped in securing acceptance, that were dedicated to the project and were therefore not distracted by other commitments. These teams were also based at the "center" of the institution, which helped in coordination and avoided fragmentation of ideas and practice by more devolved approaches.

Changing Cultures. A senior lecturer in University A believed that the University lived "a bit in the past," with a culture that needed to change to meet the opportunities and challenges of the future. In University $\mathrm{B}$, a primary objective of the lean project was to achieve cultural change and to challenge the existing ways of doing things. Staff in both universities argued that lean processes could only succeed if they were truly embedded within the culture of the organization. Thus, managing cultural change was a key challenge for the universities. A senior researcher in University A emphasized that the benefits of lean applications could easily be lost if lean behaviors were not sustained. This required the management of transformational change over a long period of time. It was argued that a key to implementing cultural change was effective communication, using many different approaches (i.e., “don't rely on the website and email; get out there and talk to people”).

Benefits. In University A, the lean project was initially approved by the University Council for a three-year period, with the expectation that the formal project would be extended before being subsumed within normal working arrangements. The most important anticipated benefit at University A was to lighten the burden on staff, which could be achieved by reducing waste within processes and by improving process flow. In this way, staff time would be released to support further activity, especially in teaching and research. At University B, the lean project was seen as a long-term project to achieve sustainable cultural change that would result in improved efficiency and better processes. A lecturer at University B saw lean thinking as part of a wider vision: "We are striving to be the best we can be.” University B did not wish to benchmark itself against other institutions and was aiming to achieve "perfection.” Underlying the approach in both universities were very simple questions: "Why do we do what we do, and how can we do it better?" The benefits of lean thinking were not associated explicitly with financial objectives. Efficiency gains were related to increasing productivity and creating space in order to respond to new opportunities, and with improving quality and satisfaction by removing unnecessary delays and distractions. Savings in salaries and other costs might arise, but were not the primary perceived benefit.

Critical Factors for Success. A respondent from University A argued that "organizational readiness" was the single most important factor for success in the implementation of lean principles. In addition, it was argued that the full, active support of the senior management team was critical. At University A, a steering committee of influential leaders and managers was set up, with the explicit aim of achieving buy-in around the university. The importance of a "strong and enthusiastic" facilitation team was also stressed. In University B, it was suggested that success stemmed from choosing the right kind of projects early in the implementation period that would demonstrate potential benefits from wider applications. Moreover, the coordinating team was managerially and physically located in the vice chancellor's office, giving the project "weight and authority" in the university.

Sustaining Lean Behavior. A senior manager from University A emphasized that sustaining lean behavior required the long-term motivation and commitment of all staff. Ultimately, it was hoped that the benefits of a lean approach would encourage staff to sustain behavior and "not revert to old ways of doing things." Members of the implementation team in University B stressed the role of middle managers in achieving long-term success. In both universities, the continuing importance of senior leadership was stressed. In this context, it would be necessary for the belief in lean principles to pass from one leader to another, especially when a new vice chancellor was appointed. The interviews in both universities showed a strong belief in the application of lean principles within higher education in order to ensure competitive advantage and operational efficiency. At the same time, there was some uncertainty about the degree to which such ideas were really embedded. A senior leader in University B argued that "in a service organization, efficiency is directly related to the survival of the company, but in universities efficiency is not yet an issue of survival."

Based on the studies of Universities A and B, the relevance of lean thinking within higher education institutions is clear. Staff in both universities identified many potential benefits; and, while 
some practical difficulties in implementation were recognized, very few negatives were put forward. In this regard, the fact that lean principles were being adopted against a relatively stable financial background was highly significant. Today, as universities face increasingly severe financial difficulties, it is likely that rather more intense suspicions of the motives for and outcomes of lean thinking would emerge. While staff in both universities were very supportive of lean thinking, they also shared many doubts about the long-term position. In both cases, staff pointed to major gains, but there was also a feeling that such gains were fragile. In each case, even the most ardent enthusiasts were uncertain to what extent cultural change had really been achieved and were concerned that hard-won progress could be very rapidly reversed.

\section{Case Study III: Knowledge Management}

\section{Background}

It is widely asserted today that knowledge lies at the heart of the modern economy, where knowledge assets are the principal factors of production and where nations and organizations have to organize their knowledge assets to their best advantage. Ideas of knowledge management (KM) began to emerge in business in the 1990s, and were heavily influenced by the massive expansion of access to information and analytical power created by new computing methods, increasing expectations regarding quality and quality assurance, and new emerging ideas about human factors and human capital. There is no clear, accepted definition of KM, but Andreea M. Serban $(2002,6)$ offers two ideas that help in understanding the concept:

1. Knowledge management is about connecting people to people and people to information to create competitive advantage.

2. Knowledge management is the systematic process of identifying, capturing and transferring information and knowledge people can use to create, compete and improve.

Another definition from David Skryme $(1997,1)$ is also helpful:

Knowledge management is the explicit and systematic management of vital knowledge and its associated processes of creating, gathering, organizing, diffusion, use and exploitation. It requires turning personal knowledge into corporate knowledge that can be widely shared throughout an organization and appropriately applied.
Skryme also identifies many of the potential benefits of KM. In particular, he identifies four key organizational benefits: better and faster innovation, improved customer service, reduced knowledge loss, and improved productivity and performance.

Ideas on KM embrace a wide range of complementary themes spanning decision-making, organizational knowledge, knowledge assets, knowledge processes, technology, experiences and values. Mark W. McElroy (2000) identifies two stages in the development of KM, beginning with a view that technology can provide all the answers, but moving on to emphasize the human resource and process initiatives. Many of these ideas are brought together in Michael Stankowsky's (2005) four pillars of knowledge management: leadership, organization, technology and learning.

The creation and transmission of knowledge is central to the raison d'être of higher education institutions. However, KM implies a structured, corporate approach to the use of knowledge. KM challenges ideas of personal knowledge and ownership of data, and questions the guarding of information in order to advance personal or group priorities and agendas within; the interests of the organization as a whole are paramount. As such, KM is a business process intended to enhance the efficiency and quality of operation. Jillinda J. Kidwell, Karen M. Van der Linde, and Sandra L. Johnson (2000, 31) argued that

Using knowledge management techniques and technologies in higher education is as vital as it is in the corporate sector. If done effectively, it can lead to better decision-making capabilities, reduced "product” development cycle time (for example, curriculum development and research), improved academic and administrative services, and reduced costs.

Higher education is moving from the old culture that considers 'what's in it for me' to a new culture that says 'what's in it for the customer?' And it is developing a culture that is ready to embrace knowledge management.

Within the UK, writing in 1998, Sheila Corral suggested that KM had made little impact within the higher education sector, although she suggested that there were some signs of change. Since then, a number of authors have reported on some specific projects (see for example Slater and Moreton 2007), but an overview of the use of KM in UK higher education has been lacking.

\section{Research Findings}

In order to explore the application of KM within UK universities, seven case studies were developed, based on 18 interviews with senior academic leaders and managers. The institutions were 
selected following an earlier national survey to identify universities active in the adoption of KM. The findings may be divided into the following eight categories and summarized as follows:

Definitions. Despite higher education institutions being in the business of creating, developing and transferring knowledge through teaching and research, it was evident from the case studies that there was no clear, widely accepted definition of knowledge. This undermined attempts to use information more effectively. Moreover, interviewees in the case studies often complained that university staff assumed that KM "was what universities are already doing." The need for clear definitions and rationales for change was apparent throughout the studies.

The case studies revealed some uncertainty about the benefits of KM, even among those leaders and managers charged with implementation. This was often crucial in shaping the relative success or failure of the project. A senior staff member in University 7 admitted:

There is quite a gap between explaining what KM is and seeing how it would benefit an institution on a day-to-day basis. I do not think that I will be able to convince someone. In a sense, we have a KM strategy. I am not sure that I know myself what KM means.

Institutional Context. The case studies showed how important it was to explain fully the potential benefits of KM. Further, it was clear that the response might vary depending on the institutional context. For example, it was suggested that some universities had undergone major changes in recent years due to references made to "change fatigue." In each case considered, the decision to implement a KM strategy was made internally, motivated by a desire to enhance operational efficiency by the more effective use of knowledge. However, given the pace of change, the range of initiatives and the resources required, some staff interviewed suggested that their colleagues questioned the rationale unless it was in response to an external directive. A contrast emerged between universities that wanted change, reflecting their ambitions and priorities (i.e., a positive view of change), and others who reluctantly entered a change process out of necessity or compulsion (i.e., a negative view of change). Significantly, in considering this distinction, the interviews showed significant differences in their attitudes to KM, and to change more generally, according to institutional and individual self-confidence.

Working Environment. A common theme running across the case studies was the need for leadership to create an environment within which staff had a positive attitude towards the institution as a whole. This does not always come easily. Most academic staff first identify with their disciplines and departments or with their research area rather than with their institutions (Becher and Trowler 2001). Senior managers believed that such attitudes could have a negative effect on implementation of institution-wide KM initiatives.

Strongly embedded traditions of working within silos was another issue identified that could work against KM. This often applied within administrative departments where significant interdepartmental barriers were identified. Interviewees argued that leadership needed to be aware of situations where the local objectives and agendas could work against institution-wide priorities. The case studies revealed many cases where information was “owned” by particular departments who were commonly reluctant to share such information with other users.

Leadership. In each case study, the importance of strong, visionary central leadership was emphasized. It was suggested that cultural change was required in order to support the implementation of KM. It was recognized that KM "would not just happen" unless leadership was committed to ensuring the necessary working environment and resources. In University 4, leadership was seen as the single most important factor influencing the success or failure of KM. It was suggested that leaders have very different backgrounds, experiences and skills they bring to their institutions, which set the tone in creating a collaborative working environment and in promoting open communications.

University 2 has worked with KM for many years and remains strongly committed to the process. In this university, the importance of leadership was emphatically confirmed. An interviewee explained how the vice chancellor had pressed the significance "of all things knowledge." In the same university, another participant indicated how the vice chancellor had promoted his own vision, but had also encouraged "bottom-up" involvement which had been helpful in securing acceptance. Moreover, getting a vice chancellor to commit to KM amid the vast range of other competing pressures was crucial.

In this context, it was suggested that academic staff were used to questioning change. Thus, evidence-based management was important. Commenting on the development of KM in University 2, a senior academic noted that

if you were to pick apart the aspects of university management that don't work terribly well in most institutions, then the first I would say is evidence-based management. A lot of the time we develop courses, we initiate reforms on gut feel, on a very limited evidential base. 
Evidence to prove the worth of new management techniques was vital in securing internal interest and acceptance.

As well as requiring leadership at a high level to provide vision and authority to the implementation process, it was also stressed that a KM project needed a senior "champion” and management team able to coordinate the project. A senior administrator in University 4 remarked on the need for "an energetic approach sympathetic to academic priorities of teaching and research; you can’t sit in your office and expect it will happen.”

Strategy. University 2 was the most experienced in the application of KM. Senior managers in this university were concerned that KM needs to be recognized within the overall institutional strategy in that "there cannot be any conflict in this respect." It was also suggested that a distinct operational KM plan was needed in order to clarify understandings of the terminology and ensure that the KM process was fully coordinated.

Another important factor identified in several case studies was the use of appropriate language. University 6 had developed a KM strategy to guide the implementation process. In the development process, much discussion had surrounded the use of the word "management." The institution concluded that use of this word was divisive within the academic community and had proved to be a distraction. As a result, alternative words were used. Clarity in the use of terminology was also important. In University 7, one academic expressed the view that

senior managers struggle with the terms. They struggle to understand, what is an information management strategy? What is a knowledge management strategy? As against this, everyone understands what a finance strategy is.

Resources. It was clear from the case studies that in the past universities were not known to prioritize and invest huge sums of money on administrative systems. However, leaders and managers now believe that they must tackle questions of student experience; new ways of working are necessary to streamline processes and increase efficiency. KM might improve the quality of services and, potentially, could lead to long-term improvements in efficiency and to savings, but, in the short term, such initiatives could cost money. A KM agenda requires the investment of money, but also requires the investment of time. Given the increasing pressure on university staff to do more with less and to incorporate market-like behaviors into their work, a KM project might be seen as an unwelcome distraction. However, for a KM project to succeed, such challenges would need to be faced.
Staff Development. An important issue highlighted by Universities 2 and 6 was the need to support a KM project with an effective staff development program. This helped to secure understanding of the benefits of KM and acceptance of change, as well as widening the appropriate skill base in the institution.

Organizational Structure. The management structure and style of the case study universities varied widely. Universities 3 and 5 implemented highly devolved structures, but these were not necessarily seen as helpful for the implementation of KM. Structures were seen to have a direct effect on $\mathrm{KM}$, especially as $\mathrm{KM}$ assumed a high level of sharing. One interviewee commented that

The money and power resides with the schools, and hence the frustrating thing is that not much of a budget is kept at the top level and hence when the top level needs to do anything across the institution you need to get heads of schools on board and then only will progress be made. This is a very slow process.

The case studies consistently emphasized the importance of good communication in implementing a major KM project. However, this was clearly a problem in some of the institutions considered. One dean complained that the rollout of KM had been frustrated by duplication of effort and unwillingness to collaborate; "something happens in one school which can impact on another but they do not know about it."

The first two sub-projects dealing with the Balanced Scorecard and Lean Thinking prompted responses from those concerned that were unequivocally positive, stressing the value of the tool(s) in question, without any hint that the technique was a passing phase or fad. By contrast, several interviewees in the sub-project dealing with Knowledge Management were much less convinced. While there was no question about the potential benefits from the more effective use of information, especially in the quality of institutional decision-making and in the effectiveness and efficiency of service delivery, some interviewees were uncertain about the precise methodology in question. KM lacks the process rigor and discipline developed for the other techniques and was widely viewed as a rather "vague and ambiguous" concept.

\section{Conclusion}

This article aims to explore the application of new management tools in UK universities and to consider whether such tools are making a real impact on higher education management. First, it is important to recognize that universities are clearly looking to improve their management practice, driven by a desire to enhance service quality and efficiency. Based on the case studies, this drive 
reflects both a genuine desire to do things better and a wider recognition of the impact of an increasingly competitive working environment with increasingly demanding stakeholders, especially students. While the case studies in this paper cover the whole of the UK, the English universities in particular were more compelled to look closely at their service provision and cost base due to changes in student funding and increases in fees. Debate continues about recognition of students as customers or consumers, but the evidence from these case studies suggests very strongly that universities are now acutely aware of the need to meet student expectations and confirms the shift of higher education from a supply driven activity to a demand led function. This shift is incomplete and varies between institutions, but the trend in this direction is clear, and new management techniques are reinforcing this movement. New financial pressures facing universities, especially reductions in public funding, are also encouraging universities to look for new methods with which to understand and manage their activities. Understanding the cost base has become an essential element within institutional management. The application of lean thinking, for example, can be used simply to save money by reducing duplication and waste. However this is also a narrow view; more broadly, lean principles can help universities to undertake routine tasks quicker and better, and thereby help universities and their staff to find time for other opportunities.

New management tools inevitably vary in their relevance and longevity. Based on the interviews undertaken as part of this project, it would be false to see the Balanced Scorecard or Lean Principles as "fads or fancies," adopted as a fashion and likely to wither away over time. While it is certainly true that such techniques often spread by imitation and therefore appear to form a trend moving through higher education, the motivation is almost always positive, based on a sincere desire to enhance operational efficiency. In the case studies reviewed, staff, many of whom had been cynical from the outset, were often passionate converts to the strengths of new management tools and now regard their use as a permanent part of university management.

This article began with an assumption that the use of new management tools would also lead to further conclusions about the management of change in higher education. In each of the case studies, interviewees spoke openly about the conditions needed for the successful implementation of change. First and foremost, the importance of leadership is emphasized. Leadership should provide vision and ambition, but leaders should also provide relevant expertise, should be high profile advocates for the change proposed and should have acute political awareness, able to overcome obstacles both by powers of persuasion and by the creation of strategic alliances. The case studies also show the importance of leadership operating at all levels in the university, especially embrac- ing the leaders or heads of operational units. The second key message is the importance of communications and using a variety of tools, including personal one-to-one contacts. Consistency of approach and sensitivity in the language used are both emphasized. In particular, it is clear that new management tools cannot simply be "lifted" from business and applied within higher education institutions. While universities share many characteristics with business organizations and are increasingly focused on the imperatives of efficiency and quality enhancement, there are also important differences, notably the multiplicity of objectives, the absence of an explicit profit-motive and the deep-rooted, much cherished commitment to academic freedom which serves to confine the implementation of corporate change. As a result, new management tools need both careful explanation and justification and adaptation to specific, local requirements. Finally, the case studies show the importance of careful management to ensure successful implementation. Interviewees spoke eagerly about the input and guidance received from enthusiastic, proactive and well-informed university managers, but are also highly critical of cases where academic staff were left without support and assistance. In particular, the potential risks in implementing new management tools arising from highly devolved structures are identified. These key themes are summarized in Figure 1.

The case studies prompt many interesting conclusions about the implementation of new management tools. However, the study points also to wider, highly significant trends. All three tools studied emphasize the role of the university as a service organization, where the needs of stakeholders are paramount. In particular, certainly in these three case studies, the student was most certainly seen as a customer who might be attracted elsewhere, who wanted value for money and whose opinions would be important in sustaining institutional brand and reputation. The institutions studied accepted that higher education had shifted from a primarily supply-driven activity to one that was now increasingly demanddriven. Associated with these changes in underlying philosophy were strong pressures to increase operational efficiency; in effect, the challenge of 'doing more, better, with less.' In part, this reflected financial pressures, but changes in this direction were also influenced by a desire to make services more responsive and to improve quality in decision-making and in service delivery. Working within an increasingly competitive environment, efficiency of operation was seen to be a means to responding positively, quickly and flexibly to new opportunities in teaching and research (i.e., creating space for movement). Further, faced by new forms of public accountability and new responsibilities to both internal and external stakeholders, efficiency of operation is now critical and widely expected (i.e., complacent acceptance of traditional working practices could no longer be accepted). The application of new 
management tools, some with immediate success and some still unproven, was a key element within these far-reaching changes.

Figure 1. Application of New Management Tools: A Model for Implementation

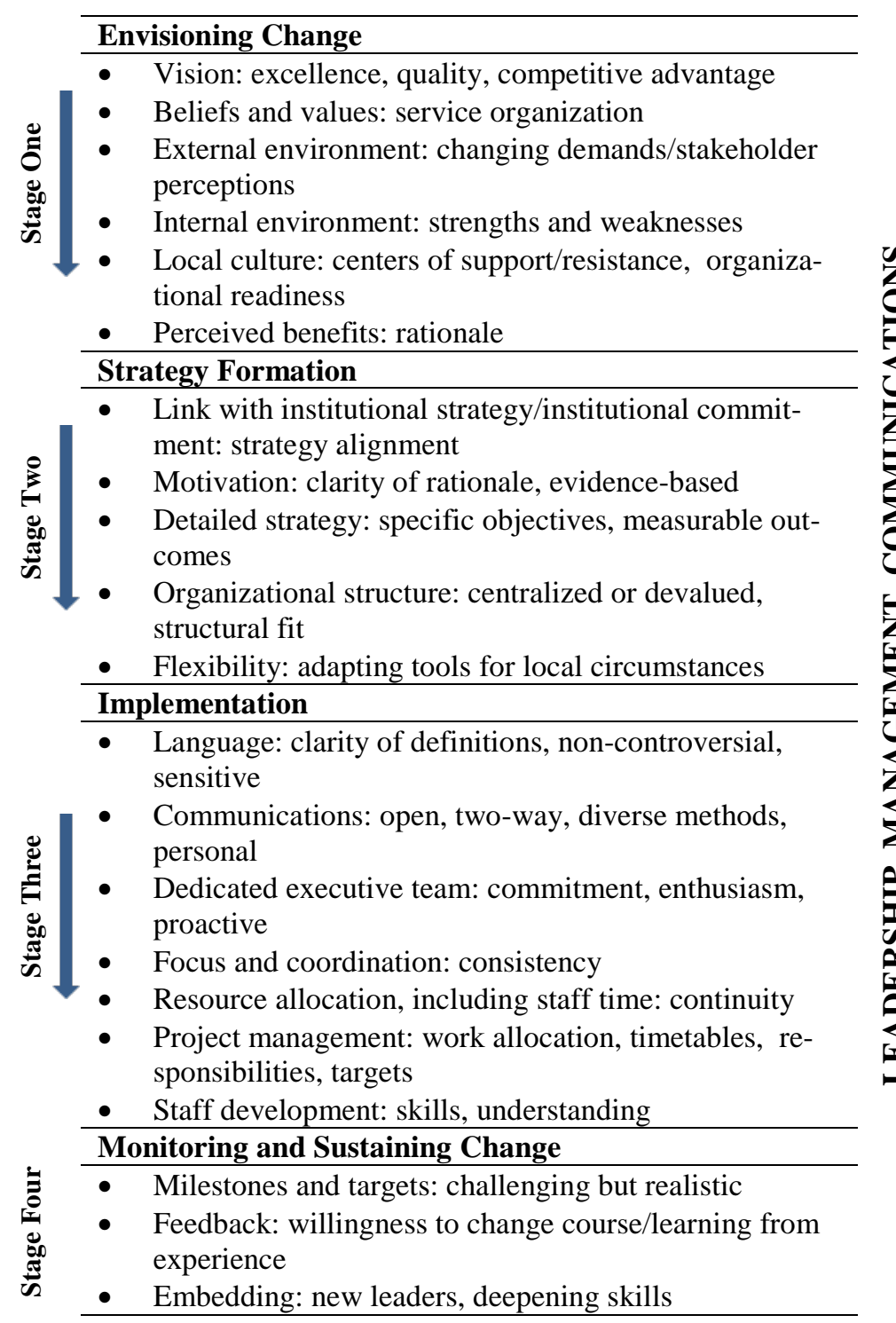

Source: Created by Author.

\section{References}

Anderson, Karen, and Rodney McAdam. 2004. "A Critique of Benchmarking and Performance Management: Lead or Lag?” Benchmarking: An International Journal 11 (5): 465-483.

Becher, Tony, and Paul R. Trowler. 2001. Academic Tribes and Territories. Buckingham: Open University Press.

Bicheno, John. 2004. The New Lean Toolbox: Towards Fast, Flexible Flow. Buckingham: PICSIE Books

Comm, Clare L., and Dennis F. X. Mathaisel. 2003. "Less is More: A Framework for a Sustainable University.” Interna- tional Journal of Sustainability in Higher Education 4 (4): 314-323.

Comm, Clare L., and Dennis F. X. Mathaisel. 2005a. "A Case Study in Applying Lean Sustainability concepts to Universities." International Journal of Sustainability in Higher Education 6 (2): 134-146.

Comm, Clare L., and Dennis F. X. Mathaisel. 2005b. “An Exploratory Study of best Lean Sustainability Practices in Higher Education.” Quality Assurance in Education 13 (3): 227-240.

Corral, Sheila. 1998. "Knowledge Management." Ariadne 18. Available online at www.ariadne.ac.uk.

Deem, Rosemary. 2001. "Globalisation, New Managerialism, Academic Capitalism and Entrepreneurialism in Universities: Is the Local Dimension Still Important?" Comparative Education 37 (1): 7-20.

Deem, Rosemary, and Kevin J. Brehony. 2005. "Management as Ideology: The Case of 'New Managerialism' in Higher Education." Oxford Review of Education 31 (2): 217-235.

Emiliani, "Bob.” 2004. "Improving Business School Courses by Applying Lean Principles and Practices.” Quality Assurance in Education 12 (4): 175-187.

Hall, Robert W. 1983. Zero Inventories. Sydney: McGraw Hill.

Hayes, Robert H., and David A. Garvin. 1982 "Managing as if Tomorrow Mattered.” Harvard Business Review 60 (1): 70-79.

Hines, Peter, Sarah Lethbridge, and Lucy O’Grady. 2007. “Creating a Lean University.” Paper presented at International Symposium of Logistics, Budapest, Hungary, 8-10 August 2007.

Kaplan, Robert S., and David P. Norton. 1992. "The Balanced Scorecard - Measures that Drive Performance.” Harvard Business Review 70 (1): 71-79.

Kaplan, Robert S., and David P. Norton. 1996. The Balanced Scorecard - Translating Strategy into Action. Boston: Harvard University Press.

Kaplan, Robert S., and David P. Norton. 2001. The Strategy Focused Organization: How Balanced Scorecard Companies Thrive in the New Business Environment. Boston: Harvard University Press.

Kidwell, Jillinda J., Karen M. Vander Linde, and Sandra L. Johnson. 2000. "Applying Corporate Knowledge Management Practices.” Educause Quarterly 23 (4) 28-33.

McAdam, Rodney, and Brian Bailie. 2002. "Business Performance Measures and Alignment Impact on Strategy: The Role of Business Improvement Models.” International Journal of Operations and Production Management 9: 972-996.

McElroy, Mark W. 2000. "Second Generation KM: A White Paper.” Emergence 2 (3): 90-100.

Poppendieck, Mary. 2002. Principles of Lean Thinking. Boston: Addison Wesley Professional.

Rigby, Darrell, and Barbara Bilodeau. 2011. Management Tools \& Trends 2011. London: Bain \& Company.

Serban, Andreea M. 2002. "Knowledge Management: The "Fifth Face” of Institutional Research.” In Knowledge Management: Building a Competitive Advantage in Higher Education, ed. Andreea M. Serban and Jing Luan (pp. 105-112). London: Wiley. 
Skinner, Wickham. 1974. The Decline, Fall and Renewal of Manufacturing Plants. Issue 38 of Working Paper. Cambridge, MA: Harvard University, Graduate School of Business Administration.

Skyrme, David. 1997. "Knowledge Management: Making Sense of an Oxymoron." Insights 22. Available online at: www.skyrme.com.

Slater, Anne, and Robert Moreton. 2007. “Knowledge Management in Higher Education: A Case Study in a Large Modern UK University.” In Advances in Information Systems Development: New Methods and Practice for the Networked Society (vol. 2), ed. Wita Wojtkowski, W. Gregory Wojtkowski, Jože Zupančič, Gabor Magyar, and Gabor Knapp (pp. 371-382). New York: Springer.

Stankosky, Michael. 2005. "Advances in Knowledge Management: University Research Toward an Academic Discipline.”
In Creating the Discipline of Knowledge Management: The Latest in University Research, ed. Michael Stankosky (pp. 114). Burlington, MA: Elsevier Butterworth Heinemann.

Taylor, John, and Claire Baines. 2012. "Performance Management in UK Universities." Journal of Higher Education Policy and Management 34 (2): 111-124.

Womack, James P., Daniel T. Jones, and Daniel Roos. 1990. The Machine that Changed the World. New York: Simon \& Schuster.

Womack, James P., and Daniel T. Jones. 2003. Lean Thinking: Banish Waste and Create Wealth in Your Corporation. New York: Simon \& Schuster.

Womack, James P. 2006. "Lean Thinking for Education.” Keynote address at EdNet Annual Meeting, Worcester, MA, 17 October 2006. 